\title{
When Starting a MICS Program, Don’t Assume Excellence: Prove It!
}

Rachel Eikelboom ${ }^{1}$, Rashmi Nedadur ${ }^{2}$, Roberto Ribeiro ${ }^{2}$, and Bobby Yanagawa ${ }^{3}$

${ }^{1}$ Affiliation not available

${ }^{2}$ University of Toronto

${ }^{3}$ St Michael's Hospital

January 8, 2021

Commentary:

When Starting a MICS Program, Don't Assume Excellence: Prove It!

Rachel Eikelboom $\mathrm{MD}^{1,2}$, Rashmi Nedadur $\mathrm{MD}^{3}$,

Roberto Vanin Pinto Ribeiro $\mathrm{MD}^{3}$, Bobby Yanagawa MD $\mathrm{PhD}^{3}$

${ }^{1}$ Department of Surgery, Max Rady College of Medicine, University of Manitoba, Winnipeg, Manitoba, Canada

2 Division of Cardiac Surgery, McMaster University, Hamilton, Ontario, Canada

${ }^{3}$ Division of Cardiac Surgery, St Michael's Hospital, University of Toronto, Toronto, Ontario, Canada

Corresponding author:

Bobby Yanagawa MD, PhD, FRCSC Program Director, Division of Cardiac Surgery, University of Toronto Assistant Professor, Division of Cardiac Surgery, St. Michael's Hospital 30 Bond Street, 8th Floor, Bond Wing Toronto, ON M5B 1W8 Canada Tel: 4168645706 Fax: 4168645031 Email: yanagawab@smh.ca

Word count: 430

Conflict of interest: The authors have no conflict of interest and have not received any funding.

Central Figure: 


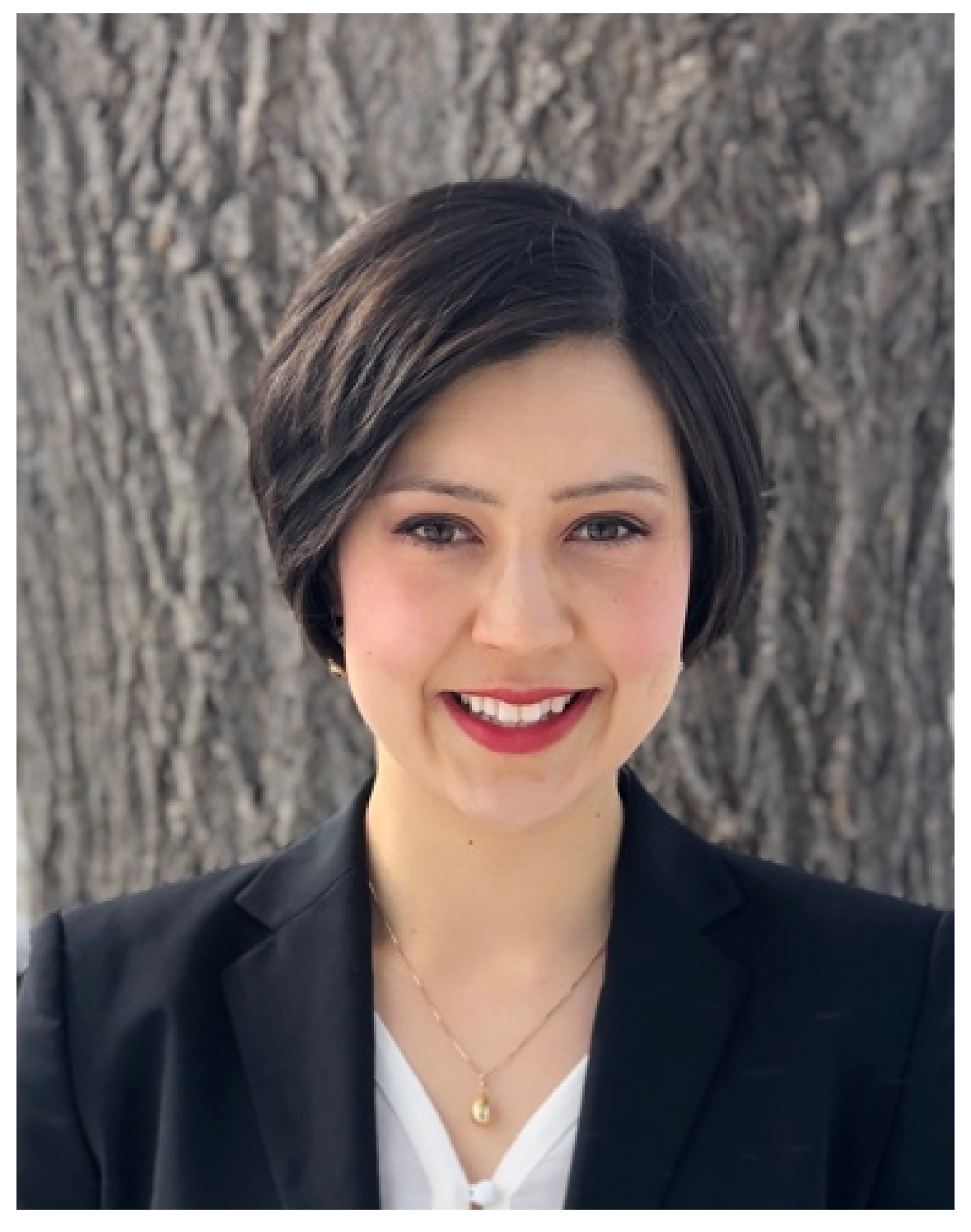




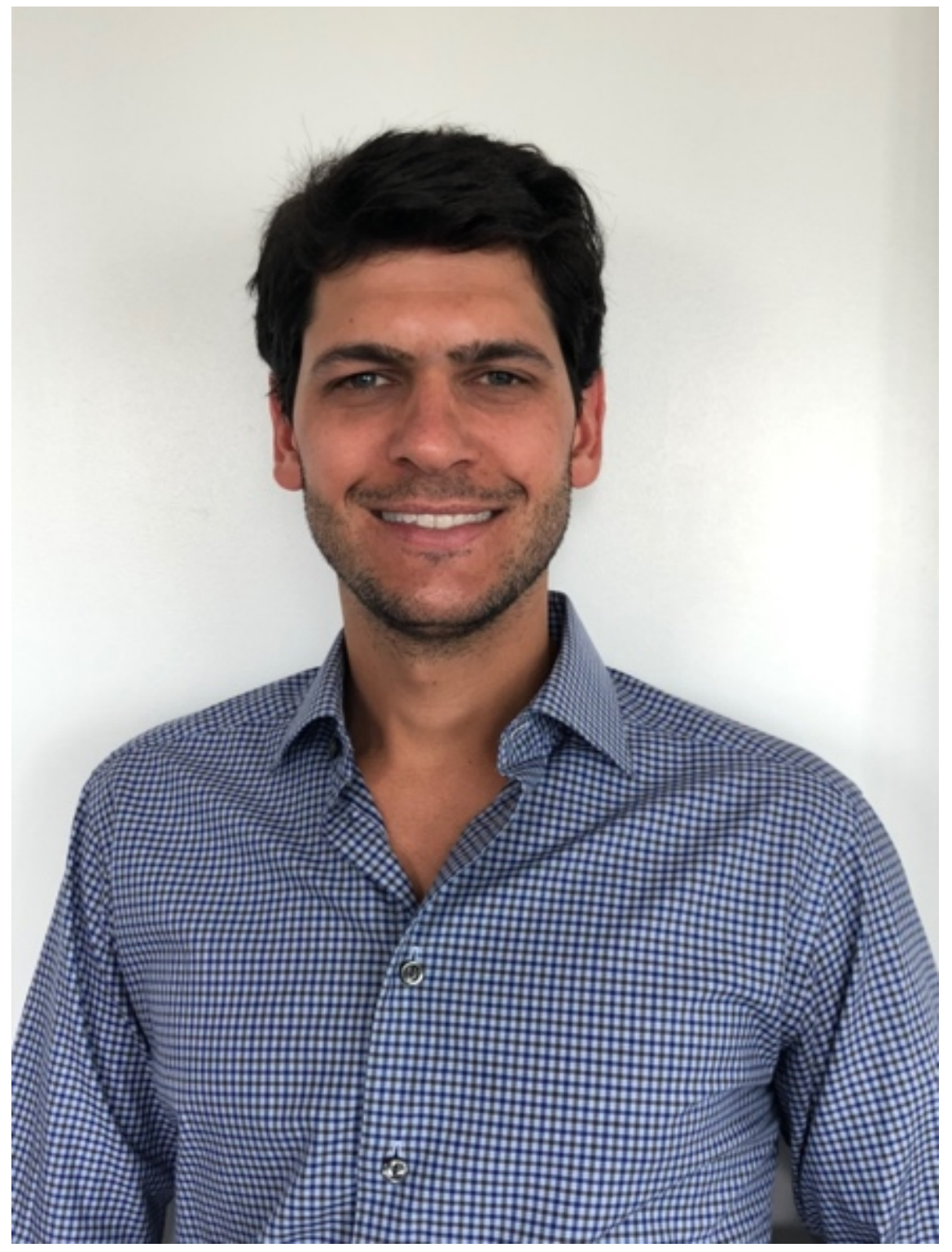




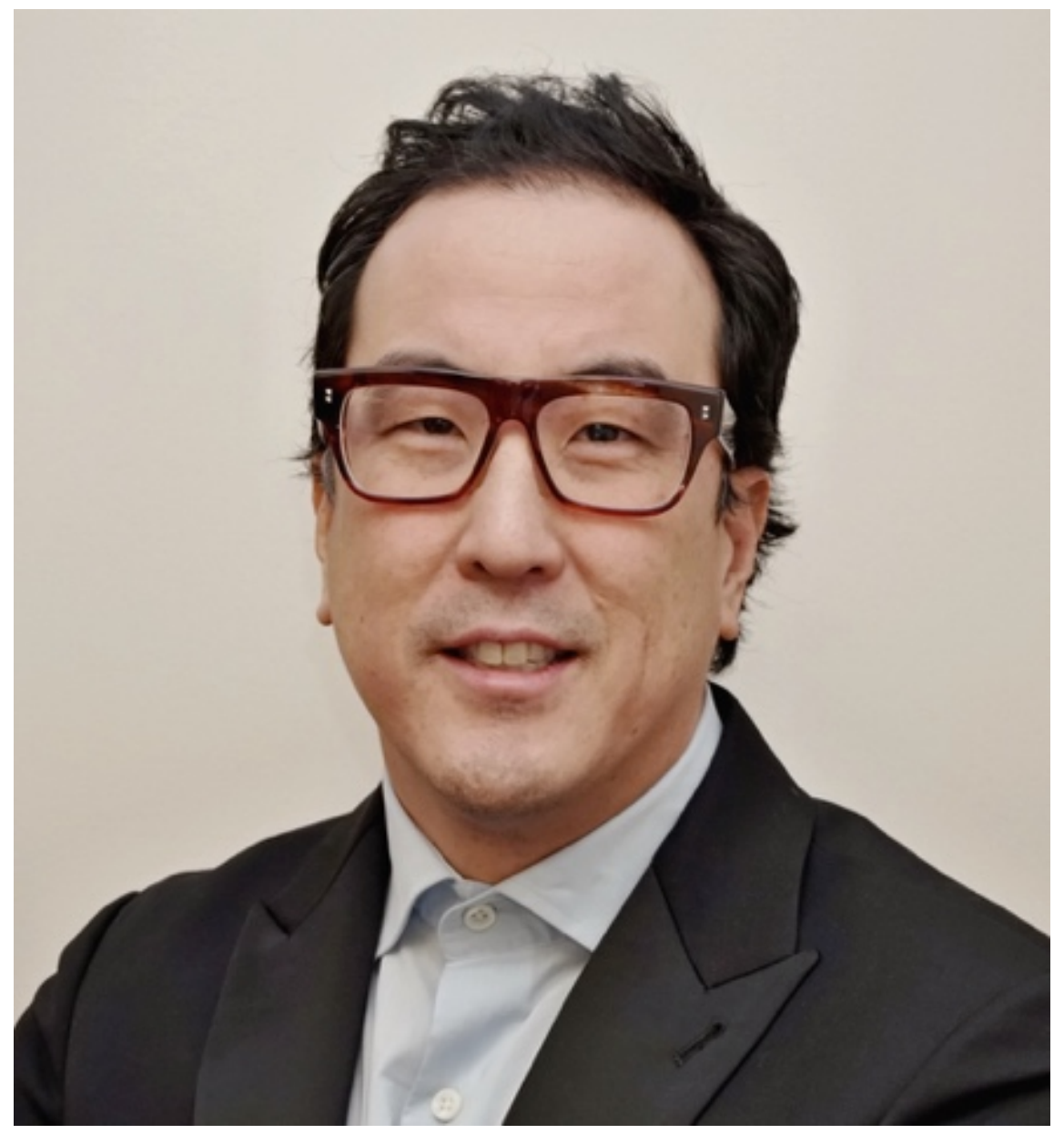




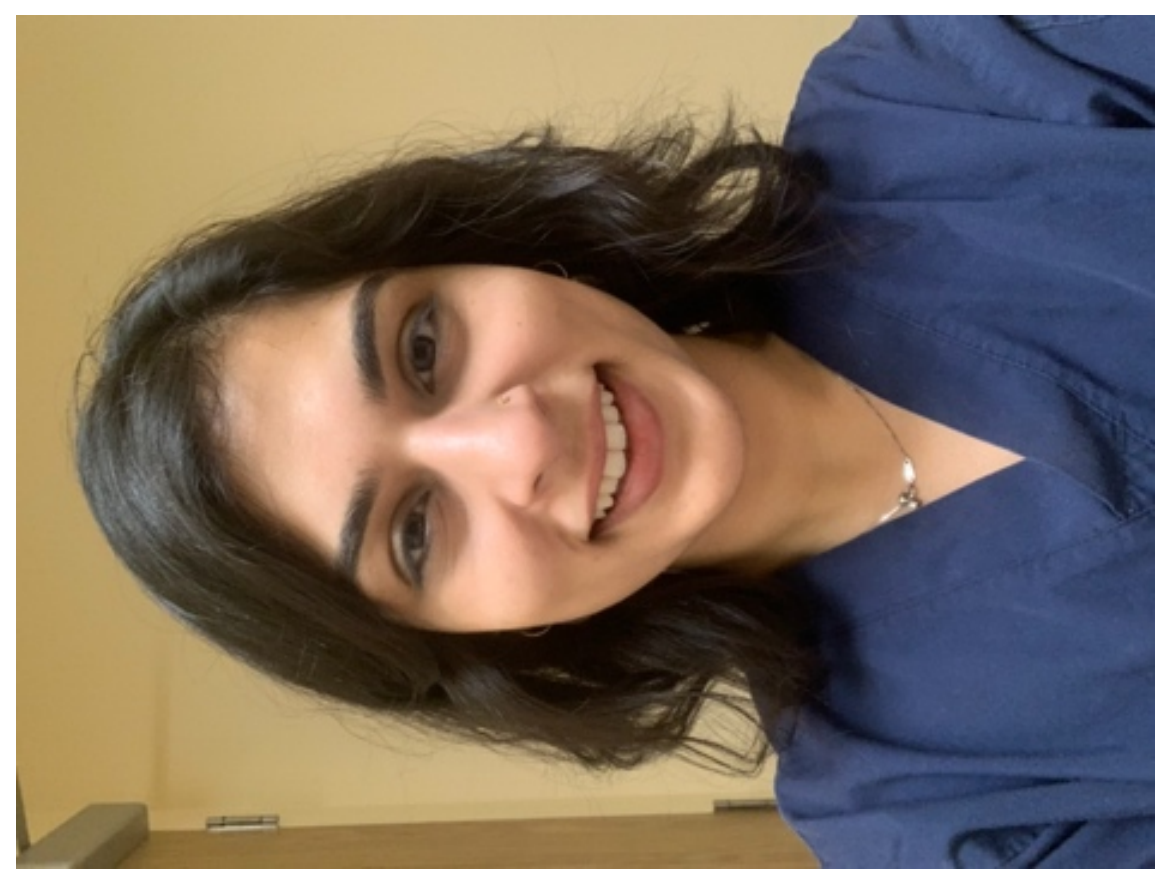

Figure Legend:

Rachel Eikelboom, Rashmi Nedadur, Roberto Vanin Pinto Ribeiro, Bobby Yanagawa (Left to Right)

We congratulate Zhang and colleagues on their successful minimally invasive multivessel coronary artery bypass surgery (MICS CABG) program. ${ }^{1}$ They present a series of 186 consecutive patients who underwent MICS CABG by expert surgeons at their center. They report excellent graft patency and complete revascularization (CR) rates. Graft patency was assessed by protocolized pre-discharge coronary angiograms, demonstrating overall $96 \%$ patency. Complete revascularization, as defined as number of grafts performed compared to the surgeon's preoperative plan, was achieved in all but one patient. These are world-class results for conventional CABG, let alone MICS CABG.

Zhang and colleagues' series illustrates important principles in the establishment of a MICS program. First, the quality of MICS surgery should be as good as the conventional technique. Here, the surgeons assessed graft patency with protocolized pre-discharge coronary angiograms, which is the gold standard for assessing patency although less invasive alternatives such as cardiac CT angiography may also be reasonable. ${ }^{2}$ Their graft patency comparable favorably to results from other conventional CABG in experienced centers. ${ }^{3}$

Next, the surgeons confirmed complete revascularization. The definition of CR include: 1) one graft per viable myocardial territory, 2) one graft to every vessel $>1.5 \mathrm{~mm}$ with a $>70 \%$ stenosis, and 3) comparison of preoperative plan to actual grafts performed. ${ }^{4}$ Here, the surgeons achieved exceptionally high rates of CR. Even in CORONARY, which randomized patients to off- versus on-pump CABG performed by expert surgeons, there was a $10 \%$ rate of incomplete revascularization comparing preoperative plan to actual grafts, ${ }^{5}$ compared with $99 \% \mathrm{CR}$ in this trial.

Finally, surgical procedures need to be matched to both surgeon and patient. Here, surgeons had experience in both off-pump CABG and single vessel MICS CABG before attempting multivessel MICS CABG, and this is likely why they were able to achieve such high rates of CR and graft patency. Patients were carefully selected, with a mean age of 63 and a mean BMI of 24, few comorbidities, and preserved left ventricular function.

Zhang and colleagues' approach of ensuring CR and graft patency is well thought out and should be the 
standard for all surgeons performing MICS CABG, at least for the initial cohort of patients. Long-term follow-up will be crucial in order to demonstrate continued graft patency without increased need for repeat revascularization. This excellent series demonstrates that high quality revascularization is attainable with MICS CABG and provides a blueprint for other surgeons interested in establishing a MICS program.

References

1. Zhang L, Fu Y, Gong Y, Zhao H, et al. Graft patency and completeness of revascularization in minimally invasive multivessel coronary artery bypass

surgery. J Card Surg. 2021; In Press.

2. Andreini D, Pontone G, Ballerini G, et al. Bypass graft and native postanastomotic coronary artery patency: assessment with computed tomography. Ann Thorac Surg. 2007;83:1672-8.

3. Puskas JD, Williams WH, Mahoney EM, et al. Off-pump vs conventional coronary artery bypass grafting: early and 1-year graft patency, cost, and quality-of-life outcomes: a randomized trial. Jama. 2004;291:1841-9.

4. Ong AT, Serruys PW. Complete revascularization: coronary artery bypass graft surgery versus percutaneous coronary intervention. Circulation. 2006;114:249-55.

5. Lamy A, Devereaux PJ, Prabhakaran D, et al. Off-pump or on-pump coronary-artery bypass grafting at 30 days. N Engl J Med. 2012;366:1489-97. 